\title{
Uçuş Veri Kaydedicisi Verilerinden Bulanik Mantik Yöntemi ile İrtifa Tahmini
}

\author{
Sancak Demiryürek ${ }^{1}$, Mustagime Tülin Yıldırım ${ }^{2}$ \\ ${ }^{1}$ Kapadokya Üniversitesi, Meslek Yüksekokulu, Uçak Teknolojisi Bölümü, Nevşehir, Türkiye (ORCID: 0000-0003-0035-5250) \\ 2 Erciyes Üniversitesi, Havacılık ve Uzay Bilimleri Fakültesi, Uçak Eleltrik Elektronik Bölümü, Kayseri, Türkiye (ORCID: 0000-0001-8711-5588)
}

(Bu yayın HORA 2019 kongresinde sözlü olarak sunulmuştur.)

(İlk Geliş Tarihi 1.08.2019 ve Kabul Tarihi 24.10.2019)

(DOI: $10.31590 /$ ejosat.637780)

ATIF/REFERENCE: Demiryürek, S. \& Yıldırım, M.T. (2019). Uçuş Veri Kaydedicisi Verilerinden Bulanik Mantik Yöntemi İle İrtifa Tahmini. Avrupa Bilim ve Teknoloji Dergisi, (Özel Sayı), 171-176.

\section{Öz}

İrtifa bilgisi uçaklar için emniyetli uçuşun temel unsurlarından birisidir. Uçuşun güvenli seviyede seyredebilmesi için altimetre pilotlara bilgi sağlayan temel uçuş aletlerinden birisi olarak kullanılmaktadır. Altimetre kaynaklı daha önceleri meydana gelen uçak kazaları bu durumun önemini ortaya koymaktadır. İrtifa bilgilerini elde edebilmek için uçaklarda Pitot-Statik Sistem ve Hava Veri Bilgisayarına ihtiyaç duyulur. Temelde bir baromere olan altimetre uçağın deniz seviyesinden yüksekliğini ölçmektedir. Atmosfer katmanındaki bazı bozucu etmenlerle birlikte coğrafik etkilerden dolayı irtifa ölçümlerinde sapmalar oluşmaktadır. Altimetre sistemi herhangi bir bozucu etken karşısında tüm yedek sistemleriyle birlikte etkilendiğinden emniyetli uçuş için alternatif bir sisteme ihtiyaç duyulmaktadır. Bu çalışmada amaç bozucu unsurlardan etkilenmeyen, altimetreden ayrı bir sistemden alınan ivme verilerini, zaman domeni kullanarak giriş parametreleri elde etmektir. Bu parametrelerden ivme verisi acil durum elektrik sisteminden beslenen, diş bozucu unsurlardan etkilenmeyen, kalibrasyon ve bakım gerektirmeyen ivme ölçer sisteminden temin edilmektedir. Bir başka dış sebeplerden etkilenmeyen parametre olan zaman domeni de bulanık mantık sistemine giriş olarak tanımlanmıştır. Önerilen çalışmada iki girişli bir çıkışı bulanık mantık yöntemi kullanılarak Genelleştirilmiş Çan Tipi ve Gauss Fonksiyonu ile irtifa tahmini yapılmış, elde edilen sonuçlara göre performans kıyaslaması gerçekleştirilmiştir. Kıyaslama neticesinde Gauss fonksiyonunun Genelleştirilmiş çan tipi fonksiyonuna göre daha iyi performans gösterdiği gözlemlenmiştir. Gauss fonksiyonunun üretmiş olduğu irtifa bilgisi Genelleştirilmiş çan tipi fonksiyonunun üretmiş olduğu irtifa bilgisine göre \%95 daha az hata çıkardığı gözlemlenmiştir. Önerilen yöntemin avantaj1, Hava Veri Bilgisayarında kullanılan düzeltme parametrelerine gerek kalmaksızın, Pitot-Statik Sistemde oluşacak arızalardan ve coğrafi etkilerle birlikte hava muhalefetinin oluşturmuş olduğu bozucu unsurlardan etkilenmeyen; uçuş veri kaydedicisi verilerinden bulanık mantık yöntemi ile irtifa tahmini yapan alternetif bir sistem ve hesaplama mantığı getirmesidir.

Anahtar Kelimeler: İrtifa tahmini, bulanık mantık, uçuş veri kaydedicisi, altimetre.

\section{Altitude Estimation from Flight Data Recorder Data by Fuzzy Logic Method}

\begin{abstract}
Altitude information is one of the basic elements of flight safety for an aircraft. Altimeter is used to provide informatiopn by pilots as one of the basic flight insturments in order to cruise within flight safe limits. This case emphasizes the impotance of flight accidents happened due to altimetre that are welded. In order to obtain altitude information from aircraft Pilot-Static system and air data computer is needed. The aircraft altimeter is basically a barometer which measures the height with upon sea level. Some destructive factors and geographical factors in the layers of the atmosphere that consists of measurements due to deviations in altitude. The altimeter with its all back-up system is affected in the case of disruptive factor that is why it is needed to have an alternative system for the flight safety. The purpose of this study is to obtain access parameters using time domain that are acceleration data gained from different altimeter sytem and not affected by disruptive factors. Emergency acceleration data fed by the electrical system of these parameters, which are not affected by external destructive elements, do not require system calibration and maintenance supplied from the accelerometer. Another Fuzzy Logic, which is a parameter, is not affected by external causes in time domain defined as the input to the system. In the

${ }^{1}$ Corresponding Author: Kapadoktya Üniversitesi, Kapadokya Meslek Yüksekokulu, Uçak Teknolojisi Bölümü, Nevşehir, Türkiye, ORCID: 0000-

0003-0035-5250, sancakde@gmail.com
\end{abstract}


proposed study, two-input one-output Fuzzy Logic can be generalized by using the method-type and the Gaussian function with the performance comparison have been conducted according to the results that are gained from the study. As a result of benchmarking, the Generalized Bell function of the type of the Gaussian function showed better performance than observed. The altitude of the Gaussian function can be Generalized by the function that generated the type of knowledge produced that are based on the information of altitude is $95 \%$, it is observed that fewer errors are made. The advantage of the proposed method, the correction parameters used in the Air Data Computer, without the need to Pitot-Static system faults in air and geographical elements that have created the destructive effects are not affected by the opposition of the flight data recorder altitude estimated from the data with which an alternative method of Fuzzy Logic System, so ultimate aim is to have an alternative sytem and calculation perspective for altitude estimation.

Keywords: Altitude estimation, fuzzy logic, flight data recorder, altimeter.

\section{Giriş}

Günümüzde havacılığın ulaştırma alanında bu denli öneme sahip olmasındaki en önemli faktör uçuş emniyetidir. Bir uçağın seyir sırasında uçuşunu emniyetli şekilde idame ettirebilmesi için bazı uçak sistemlerine ve pilotlara yardımcı olacak göstergelere ihtiyacı vardır. Bu asgari kokpit göstergeleri olarak bilinen "BASIC-T”" adında temel T formatındaki Hava Hız Göstergesi, Durum Göstergesi, Altimetre ve Pusuladır[1]. Bunlardan bir tanesinin olmaması veya hatalı çalışması durumunda uçuş güvenli gerçekleşemez ve kaza kırımla sonuçlanabilir. Çalışmamızın konusu olan Altimetre uçağın seyir irtifasını belirten bir seyrüsefer kokpit aletidir [2]. Bu alet uçağın belli coğrafik yükseltilerin üzerinde uçarken deniz seviyesinden ne kadar yüksekte olduğunu ölçmekle birlikte, kalkışta hangi irtifaya tırmanacağını ve inişte piste ne kadar mesafeyle ineceği hakkında pilotlara bilgi sağlamakta ve yardımcı olmaktadır.

Altimetrenin temel çalışma prensibi deniz seviyesinden ölçüm yapan barometreler gibidir [2]. İçerisine sıkıştırılmış Aneroid basınç kapsülünün deniz seviyesindeki 1013,25 mb, 14,7 PSI, 29,92 in/Hg değerindeki hava basıncı sayesinde yerden yükseldikçe kapsül üzerine etkiyen hava basıncının azalmasıyla kapsül genleşir ve bu değişim miktarı ölçeklendirilmiş gösterge skalasına yansıtılır [3]. Teknolojinin gelişmesiyle birlikte yeni nesil uçaklarda Hava Veri Bilgisayarı kullanılmaya başlanmıştır [4]. Bu bilgisayar mekanik Altimetreye alternatif olarak üretilmesi, atmosferin her katmanında değişen hava basıncı ve değişken hava olaylarının etkisinde kalan mekanik Altimetrenin hassas değerler gösterememesinden dolayı hesaplanmış düzeltme tabloları kullanarak gerçeğe yakın irtifa ölçümü yapmaktadır [5]. Ölçüm yapan Hava Veri Bilgisayarı basınç bilgisini Pitot-Statik Sistemin öğesi olan Statik Sistemden almaktadır [6]. Bu sistemlerin her biri ayrı ayrı Hava Veri Bilgisayarına bilgi sağlar. Uçak üzerine etki eden coğrafik etkenlerden dolayı Hava Veri Bilgisayarına gelen basınç bilgisinde sapmalar meydana gelir [7]. Ayrıca hava muhalefeti olan bir bölgede uçuş yapılıyorsa dengesiz atmosfer basıncı doğrudan Statik Sisteme yansımakta; bu durumdan kaynaklanan hesaplama hatası kokpitteki göstergelere ve otopilot sistemine yansımaktadır. Uçuş emniyetini tehlikeye düşüren bu gibi durumlardan kaynaklı pek çok uçak kazası yaşanmıştır (örn; Boeing 757 Birgen Air-6.2.1996, Airbus 330 Air France-1.6.2009, ...). Bu kazaların önüne geçebilmek için sistemler yedeklenmiş ve her yedek bilgisayarın bilgi aldığı portun ayrı olması sağlanmıştır. Sistemler yedekli olsa bile aynı yöntemle ölçüm yapan yedek sistemin de atmosferden gelebilecek bilinmedik bozucu etkilerden dolayı yanlış ölçüm yapması ihtimali bulunmaktadır. Bu olumsuz etkiyi kaldırabilmek için sistemsel olarak ve çalışma mantığı olarak farklı şekilde çalışan, alternatif bir sistem üretme gerekliliği doğmuştur. Bu sistemin uçak sistemi içerisinde çalışmasını idame ettirebilmek için elektriksel gücünü uçağın acil durum sisteminden temin etmesi, bilgiyi başka sistemden ve başka hesaplama yöntemiyle almaşnın daha uygun olacağı düşünülmüştür. Hesaplama mantığı da değişeceğinden dolayı Statik sistemden tamamen bağımsız olarak çalışan bir yedek sistem karşımıza çıkmış olacaktır.

Bahsedilen nedenlerden dolayı belirsizliklerin ortadan kaldırılması ve bozucu etkenlerin elenmesi için Bulanık Mantık yöntemi seçilmiştir. Bu çalışmada bulanık mantık yöntemiyle, Uçuş Veri Kaydedicisi sistemi üzerinden alınan İvmeölçer verileriyle zaman domeni kullanılarak irtifa tahmini ve bozucu etkilerin düzeltilmesi işlemi yapılmıştır.

\section{Bulanık Mantık Yöntemi}

\subsection{MATLAB'ta Bulanık Mantık Ara Yüzünde Giriş Çıkış Parametrelerinin Belirlenmesi}

Bulanık mantık ara yüzüne giriş parametreleri için FDR kayıtlarından alınan ivme verileri ve zaman domeni kullanılmıştır. Zaman domeni saniye cinsinden, ivme verileri G (Gravitiy) katsayısının karşılı̆̆ cinsinden kg/ $\mathrm{sn}^{2}$ olarak sistemden alınmıştır. Sonra bu değer $\mathrm{ft} / \mathrm{sn}^{2}$ cinsine çevrilip Simulink üzeriden $\mathrm{m} / \mathrm{sn}^{2}$ ye evrilerek hesaplama parametresi için kullanılmıştır. Bu iki verinin kullanılmasının amacı FDR kayıtlarına bakıldığında her veriyi saniyede bir olarak işlediğinden ve ivmenin ölçüsünün $\mathrm{m} / \mathrm{sn}^{2}$ bazında hesaplanmasıdır. 


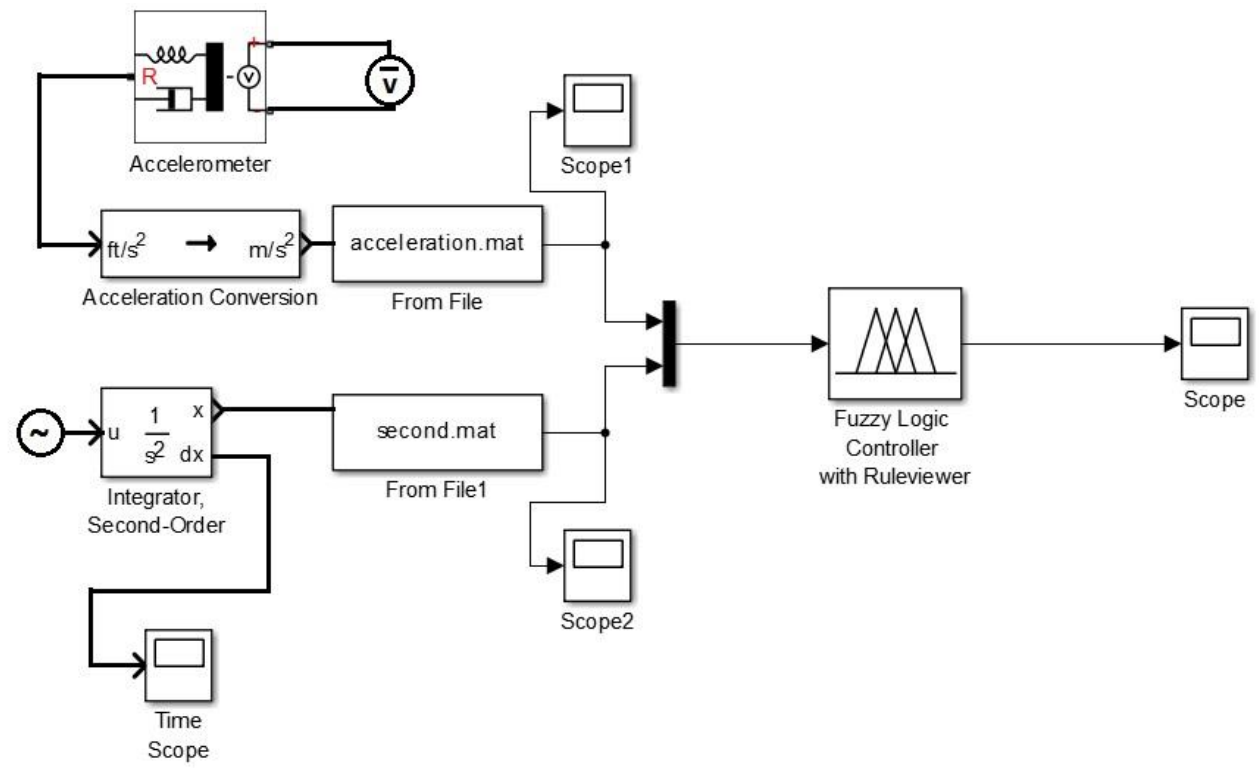

Şekil 1. Bulanık Mantık Kurallarının MATLAB Simulink Devre Şeması

Şekil 1'den görüldüğü üzere MATLAB SIMULINK üzerinden çalıştırılan Bulanık Mantık simülasyon devresine giriş olarak zaman domeni ve ivme verileri girilmiştir.

\subsection{MATLAB'de Bulanık Mantık Kural Tablosunun Belirlenmesi}

Bulanık ara yüz sisteminde giriş parametrelerinin hangi ağırlıkta çıkışa etki ettiğini belirlemek için kural tablosu oluşturulmalıdır. Bunun için iki girişli, bir çıkışlı ve üç üyelik fonksiyonu kullanılan bir sistemde aşağıdaki formüle göre kural sayısı hesaplanmaktadır:

$$
K=f^{g}
$$

Bu eşitlikte 'K' kural sayısı, 'f' üyelik fonksiyonu sayısı ve 'g' giriş sayısıdır. Bu şekilde üretilen dokuz tane kural aşağıdaki tabloda verilmiştir.

Tablo 1. Bulanık Mantık Kural Tablosu

\begin{tabular}{|c|c|c|c|}
\hline RULES: & YAVAŞ & NORMAL & HIZLI \\
\hline GENIŞ & ÇK & $\mathrm{K}$ & $\mathrm{O}$ \\
\hline ORTA & $\mathrm{K}$ & $\mathrm{O}$ & $\mathrm{B}$ \\
\hline KISA & $\mathrm{O}$ & $\mathrm{B}$ & ÇB \\
\hline
\end{tabular}

Burada ÇK; Çok Küçük, K; Küçük, O; Orta, B; Büyük ve ÇB; Çok Büyük olarak kural skalası oluşturulmaktadır. Oluşturulan bu tabloya göre girişler ağırlıklandırılarak kural tabanına yansıtılmaktadır.

\subsection{MATLAB'de Bulanı Mantı Sisteminin Üyelik Fonksiyonun Belirlenmesi}

Bulanık mantıkta hatayı bastırmak için çeşitli üyelik fonksiyonları kullanılmaktadır. Bu çalışmada hataların arındırılması ve tahmin derecesinin artırılması için Genelleştirilmiş Çan Eğrisi üyelik fonksiyonu (gbellmf) ve Gauss üyelik fonksiyonu (gaussmf) kullanılarak irtifa tahmini yapılmıştır. Giriş öğelerinde ivme verisi kullanıldığından hataların değişimini gözlemleyebilmek için ivme değişimlerinin en fazla olduğu tırmanma fazında, belirtilen iki fonksiyon ile irtifa tahmini yapılmıştır. Bu sayede uçağın tırmanış fazında bozucu etkilerden nasıl arındırılacağı gözlemlenmiş olacaktır.

\subsection{Tırmanış Fazında Üyelik Fonksiyonlarına Göre İrtifa Tahmini}

\subsubsection{Tırmanış Fazında Genelleştirilmiş Çan Ĕ̆risi Üyelik Fonksiyonuyla Irtifa Tahmini}

Bu üyelik fonksiyonunda giriş için 870 adet ivme verisi ve zaman domeni kullanılmıştır. Genelleştirilmiş Çan Eğrisi fonkisyonuyla elde edilen tahminler Uçuş Veri Kaydedicisinden alınan gerçek barometrik irtifa ile karşılaştırılarak MAD, MSE, RMSE, MAPE ve R² analizleri yapılmıştır. Elde edilen değerler aşağıdaki tabloda verilmiştir. 
Tablo 2. Genelleştirilmiş Çan Eğrisi Fonkisyonuyla Elde Edilen MAD, MSE, RMSE, MAPE ve R2 Analizleri

\begin{tabular}{|c|c|c|c|c|}
\hline MAD & MSE & RMSE & MAPE & $\mathbf{R}^{\mathbf{2}}$ \\
\hline 93283,25885 & 11688892193 & 108115,2 & 532,4316 & 0,9654 \\
\hline
\end{tabular}

Tabloda görüldüğü üzere $\mathrm{R}^{2}$ değeri 1'e yaklaşmaktadır bu ise giriş verilerinin birbirleriyle ilintili olduğunu gösterir. Bundan ötürü MAD, MSE ve RMSE değerleri ivme sapmasından etkilenmemesi ve regresyon analizinin 1'e yakın çıkmasından dolayı aşırı hata göstermiştir. Ayrıca MAPE değeri çok yüksek çıkmıştır. Tırmanma fazının toplamında 170387 feet üretilen değerlerle FDR değerleri arasında bariz irtifa farkı oluşturmaktadır. Bu irtifa farkını saniye bazında gerçekleştiğini farz edersek saniye başına 195,8 feet fark yaratır ve kabul edilebilir bir değer değildir.

Aşağıdaki grafiklerde üretilen irtifa değişimi ve Bulanık Mantık arayüzü çıkış düzlemi görünmektedir. İrtifa grafiğinde görüldüğü üzere ivmenin değişimlerinden etkilenmesi sonucu çıkışa hatalı irtifa verisi yansımaktadır.

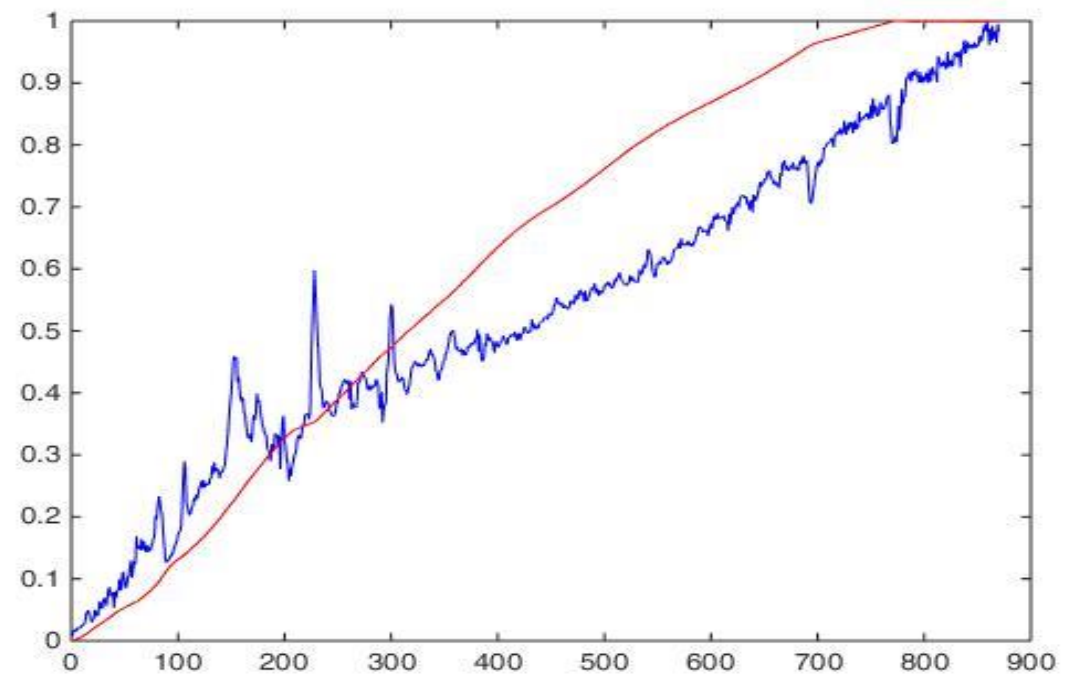

Şekil 2. Genelleştirilmiş Çan Eğrisi Fonkisyonuyla Elde Edilen İrtifa Değişimi (mavi) ve Gerçek Barometrik Değer (kırmızı)

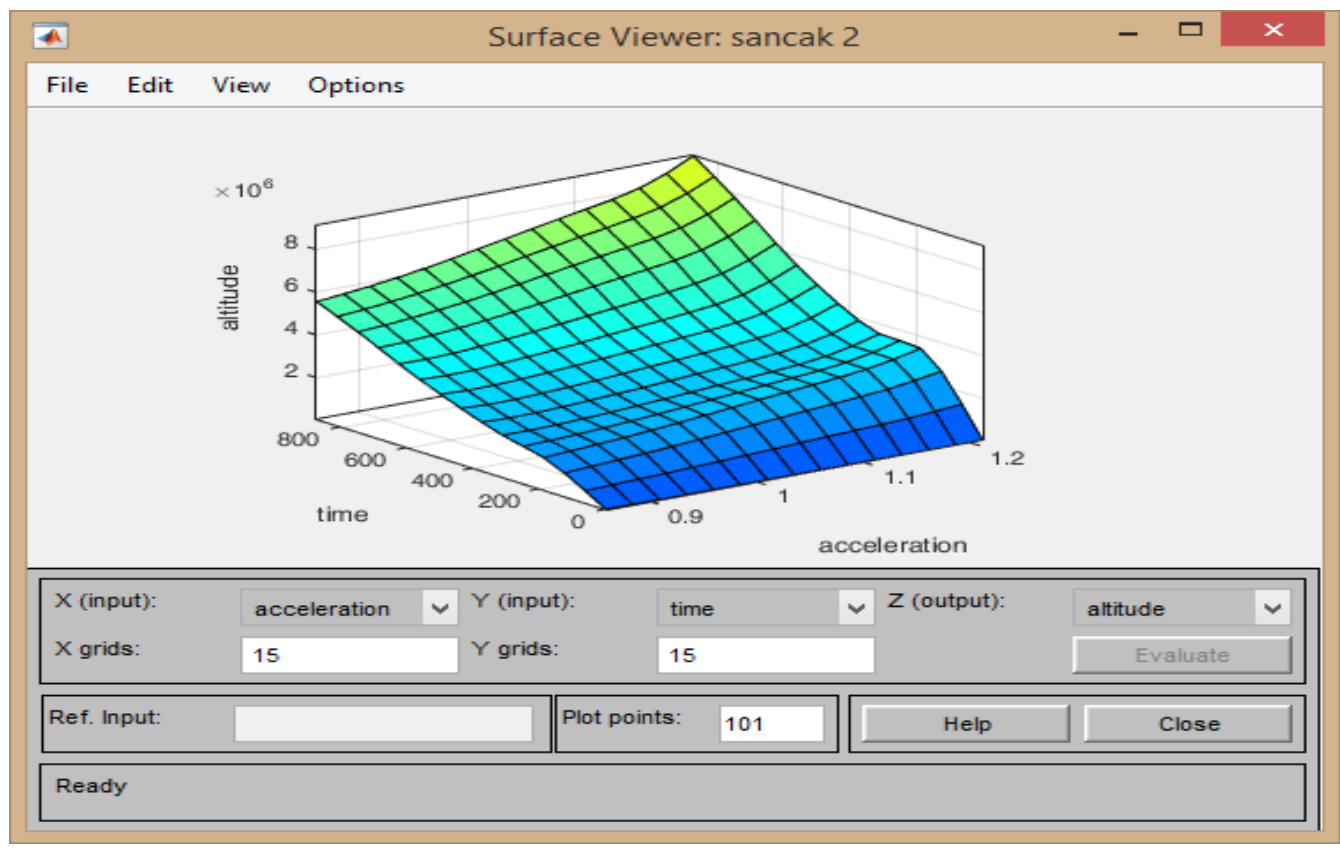

Şekil 3. Genelleştirilmiş Çan Eğrisi Fonkisyonuyla Elde Edilen Bulanık Mantık Arayüzü Çıkış Düzlemi 


\subsubsection{Tırmanış Fazında Gauss Üyelik Fonksiyonuyla Irtifa Tahmini}

Bu üyelik fonksiyonunda da giriş için 870 adet ivme verisi ve zaman domeni kullanılmıştır. Gauss fonkisyonuyla elde edilen kesitirimler Uçuş Veri Kaydedicisinden alınan gerçek barometrik irtifa ile karşılaştırılarak MAD, MSE, RMSE, MAPE ve R² analizleri yapılmıştır. Elde edilen değerler aşağıdaki tabloda verilmiş̧tir.

Tablo 2. Gauss Fonkisyonuyla Elde Edilen MAD, MSE, RMSE, MAPE ve R2 Analizleri

\begin{tabular}{|c|c|c|c|c|}
\hline MAD & MSE & RMSE & MAPE & $\mathbf{R}^{2}$ \\
\hline 3751,010207 & 18365493 & 4285,498 & 26,51104 & 1 \\
\hline
\end{tabular}

Tabloda görüldüğü üzere $\mathrm{R}^{2}$ değeri 1'dir ve giriş verilerinin birbirleriyle ilintili olduğunu göstermektedir. Bundan ötürü MAD, MSE ve RMSE değerleri ivme sapmasından etkilenmemesi ve regresyon analizinin 1 çıkmasından dolayı normale yakın seyretmiştir. Fakat MAPE değeri Genelleştirilmiş Çan Eğrisi Fonkisyonuyla nispeten düşük çıkmıştır, tırmanma fazının toplamında 8484 feet üretilen irtifa değeriyle FDR değerleri arasında belli miktar irtifa farkı oluşturmaktadır. Bu irtifa farkını saniye bazında gerçekleştiğini farz edersek saniye başına 9,7 feet fark yaratmıştır. Genelleştirilmiş Çan Eğrisi Fonkisyonun üretmiş olduğu irtifa farkının Genelleştirilmiş Çan Eğrisi fonksiyonun üretmiş olduğu irtifa farkına nazaran yirmide biri (20/1) oranındadır. Gauss fonksiyonunun hata azaltmada ve bulanık tahminde Genelleştirilmiş Çan Eğrisi fonksiyonuna nazaran daha iyi sonuçlar çıkardığı gözlemlenmiştir.

Bu değerin hesaplanmasında bize yardımcı olan Gauss fonksiyonu aşağıdaki denklemde verilmiştir:

$$
W_{i j}=\operatorname{Exp}\left(-\frac{\mathrm{dij}^{2}}{h^{2}}\right)
$$

Denklemdeki 'h' verilerin genişlik değerini ifade etmektedir. 'i' zaman domenindeki verilerin 'j' katsayısı kadar ağırlık dağılımını göstermektedir. Verinin ağırlık değerleri Gauss parabolü boyunca 'i ve j' arasındaki verinin mesafesinin artması ile azalacaktır. Veriler regresyon analizinde birbiriyle ne kadar ilintili olursa dağılım ve ağırlıklar o kadar dengeli dağılacak, gerçeğe yakın sonuçlar verecektir. Burada 'd', maksimum noktadaki verinin değerini vermektedir.

Aşağıdaki grafiklerde üretilen irtifa değişimi ve Bulanık Mantık arayüzü çıkış düzlemi görünmektedir. İrtifa grafiğinde görüldüğü üzere ivmenin değişimlerine rağmen düzeltilmiş irtifa eğrisi yansımaktadır.

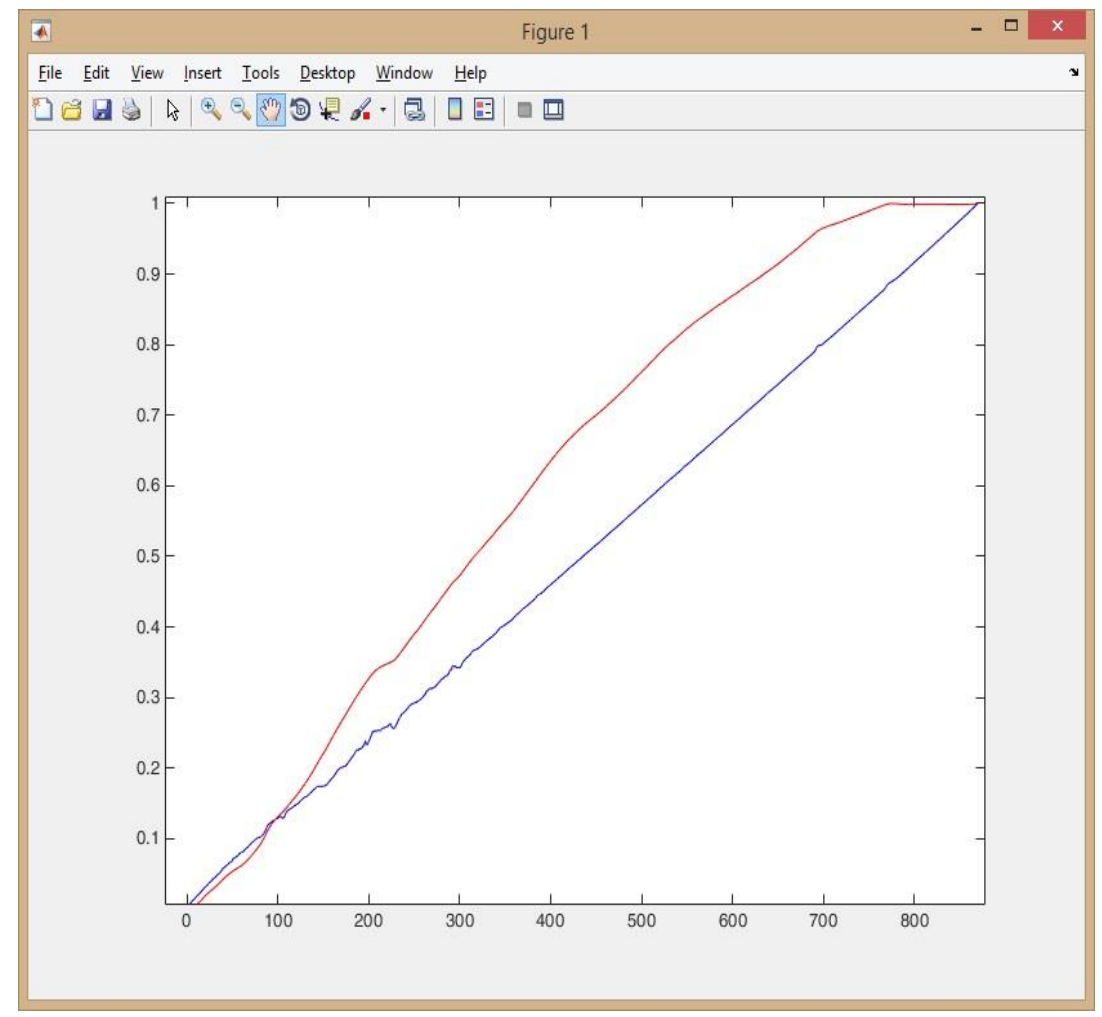

Şekil 4. Gauss Fonkisyonuyla Elde Edilen İrtifa Değişimi (mavi) ve Gerçek Barometrik Değer (kırmızı) 


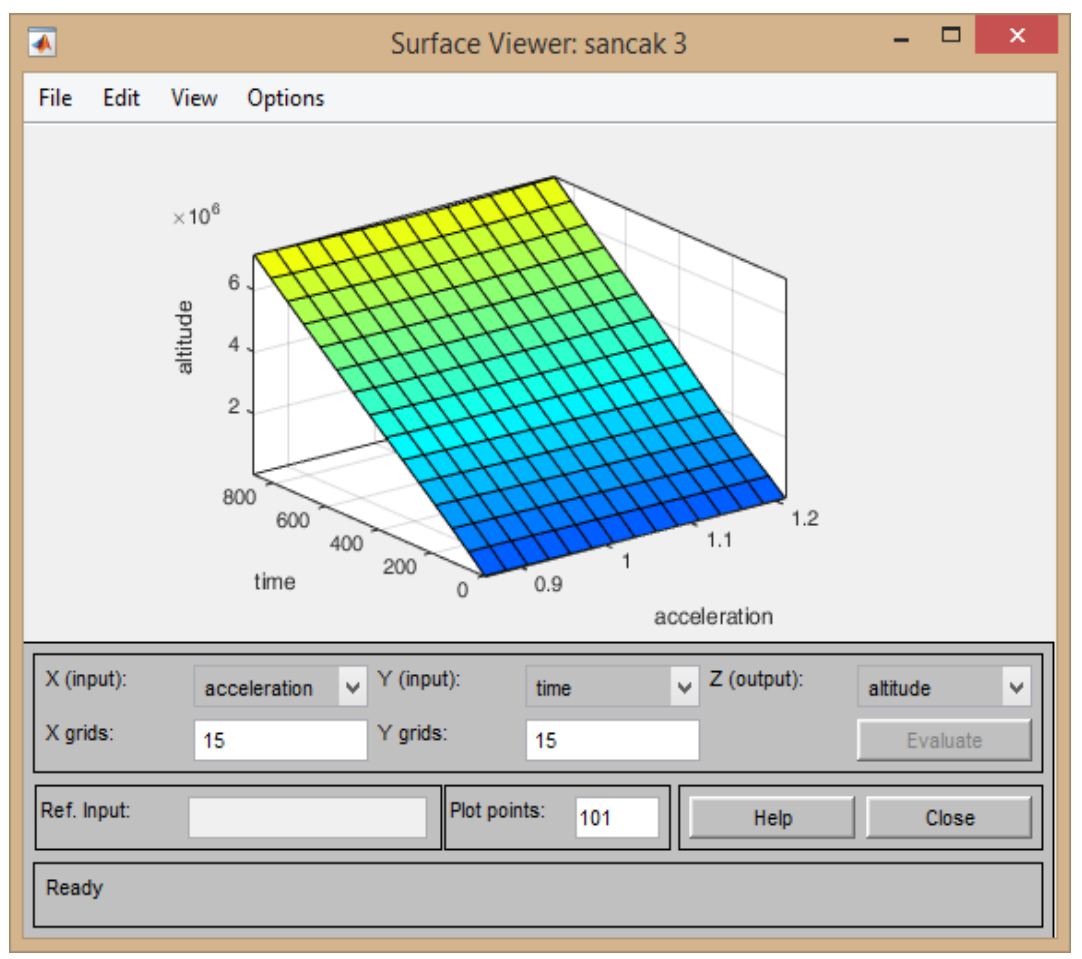

Şekil 5. Gauss Fonkisyonuyla Elde Edilen Bulanık Mantık Arayüzü Çıkış Düzlemi

\section{Karşılaştırma Sonuçları ve Öneriler}

Elde ettiğimiz sonuç neticesinde Gauss fonkisyonu ile yapılan irtifa tahmininin, Genelleştirilmiş Çan Eğrisi fonkisyonu ile yapılan irtifa tahminine nispeten daha az hata ile yapıldığını, daha iyi tahmin yapan bir hesaplama yöntemi olduğu görülmüştür. Genelleştirilmiş Çan Eğrisi Fonkisyonuyla üretilen değerlere göre Gauss fonksiyonu \%95 oranında hatayı azaltmış ve çıkışa daha lineer irtifa bilgisi yansıtmıştır. Gauss fonksiyonu kullanılarak yapılan irtifa tahmini sonuçları, Genelleştirilmiş Çan Eğrisi fonkisyonu kullanılarak yapılan irtifa tahminine göre daha iyidir.

$\mathrm{Bu}$ çalışmada sunulan yöntemin avantajı Hava Veri Bilgisayarında kullanılan düzeltme parametrelerine gerek kalmaksızın, PitotStatik Sistemde oluşacak arızalardan ve coğrafi etkilerle birlikte hava muhalefetinin oluşturmuş olduğu bozucu unsurlardan etkilenmeyen alternetif bir sistem ve hesaplama mantığı getirmesi, hızlı ve kolay hesaplama yapabilmesidir.

\section{Kaynakça}

1. EASA, 2016. TTS - Total Training Support Modüle 5.1 Volume 1 Elektronic Instrument Systems, Total Training Support Ltd, s 16.

2. EASA, 2016. TTS - Total Training Support Modüle 11.5 Volume 2 Instrument/ Avionic Systems, Total Training Support Ltd s71126.

3. "atmospheric pressure." Encyclopædia Britannica Ultimate Reference Suite. Chicago: Encyclopædia Britannica, 2011.

4. Collinson, R.P.G., Introduction to Avionics, Chapman \&Hall London, 1997,s 16 - 56.

5. Anderson, J. D., 2005. Introduction to Flight. McGraw-Hill, Fifth Edition, $1041 \mathrm{~s}$.

6. Kayton, M., Fried, W. R., 1997. Avionics Navigation Systems. John Wiley \& Sons, Inc., Second Edition, 800 s.

7. Grigorie, T.I., Dinca, L., Corcau, J.I., Grigorie, O., "Aircrafts' Altitude Measurement Using Pressure İnformation: Barometric Altitude and Density Altitude", WSEAS Transactions on Circuits and Systems, 9(7): 502-513, 2010. 